\title{
Pseudoxanthomonas mexicana sp. nov. and Pseudoxanthomonas japonensis sp. nov., isolated from diverse environments, and emended descriptions of the genus Pseudoxanthomonas Finkmann et al. 2000 and of its type species
}

\author{
Sébastien Thierry, ${ }^{1,2}$ Hervé Macarie, ${ }^{1,2,3}$ Takashi lizuka, ${ }^{4}$
} Walter Geißdörfer, ${ }^{5}$ Essokazi A. Assih, ${ }^{3,6}$ Mark Spanevello, ${ }^{7}$ Frédéric Verhe, ${ }^{3}$ Pierre Thomas, ${ }^{3}$ Ryosuke Fudou, ${ }^{4}$ Oscar Monroy, ${ }^{1}$ Marc Labat ${ }^{3}$ and Aboubakar S. Ouattara ${ }^{6}$

Correspondence

Hervé Macarie

herve.macarie@esil.univ-mrs.fr

\author{
${ }^{1}$ Departamento de Biotecnología, Universidad Autónoma Metropolitana-Iztapalapa, Avenida \\ Michoacán y la Purísima s/n, Col. Vicentina, 09340 México DF, Mexico \\ 2Institut de Recherche pour le Développement (IRD), Cicerón 609, Col. Los Morales, 11530 \\ México DF, Mexico \\ ${ }^{3}$ Laboratoire de Microbiologie IRD, IFR-BAIM, Universités de Provence et de la Méditerranée, \\ ESIL case 925, 163 avenue de Luminy, 13288 Marseille cedex 9, France \\ ${ }^{4}$ Central Research Laboratories, Ajinomoto Co., Inc., 1-1, Suzuki-Cho, Kawasaki-ku, \\ Kawasaki-shi, 210-8681, Japan \\ ${ }^{5}$ Institut für Klinische Mikrobiologie, Immunologie und Hygiene, Wasserturmstr. 3, 91054 \\ Erlangen, Germany \\ ${ }^{6}$ LAMIB-CRSBAN, Département de Biochimie-Microbiologie, Unité de Formation et de \\ Recherches en Sciences de la Vie et de la Terre, Université de Ouagadougou, 03 BP 7021 , \\ Ouagadougou 03, Burkina Faso \\ ${ }^{7}$ Leukaemia Foundation Research Unit, Queensland Institute of Medical Research, 300 \\ Herston Rd, Herston QLD-4000, Australia
}

Three mesophilic bacteria (strains AMX 26B' ${ }^{\top}$, UR374_02 and 12-3 ${ }^{\top}$ ) isolated respectively from an anaerobic digester, human urine and urban riverside soil were characterized. Cells were Gram-negative, motile, non-sporulating, straight to curved rods with one polar flagellum and had a strictly respiratory metabolism with $\mathrm{O}_{2}$ as the preferential terminal electron acceptor. Phylogenetic analysis based on 16S rRNA gene sequences revealed that all strains clustered within the Xanthomonadaceae branch of the Proteobacteria. Isolates AMX 26B' ${ }^{\top}$ and UR374_02 exhibited $100 \% 16 \mathrm{~S}$ rRNA gene sequence similarity and both were related to strain $12-3^{\top}(99 \cdot 6 \%$ similarity). The closest relative of all the isolates was Pseudoxanthomonas broegbernensis DSM $12573^{\top}$ (similarity $97 \cdot 1-97 \cdot 5 \%$ ), and they were equidistantly related to Xanthomonas species (95.4-96.6\%), Stenotrophomonas species (95.3-96.1\%) and Pseudoxanthomonas taiwanensis ATCC BAA $-4040^{\top}(95 \cdot 3-95 \cdot 4 \%)$. Chemotaxonomic and biochemical data (branched-chain cellular fatty acid pattern without $\mathrm{C}_{13: 0}$ iso $3-\mathrm{OH}$, ubiquinone with eight isoprenoid units, limited range of substrates used, ability to reduce nitrite but not nitrate with the production of $\mathrm{N}_{2} \mathrm{O}$ ) supported their affiliation to the genus Pseudoxanthomonas. The results of

Published online ahead of print on 15 June 2004 as DOI 10.1099/ijs.0.02810-0.

Abbreviation: CFA, cellular fatty acids.

The GenBank/EMBL/DDBJ accession numbers for the $16 \mathrm{~S}$ rRNA gene sequences of strains AMX 26B ${ }^{\top}$, UR374_02 and 12-3 ${ }^{\top}$ are respectively AF273082, AY124375 and AB008507.

Transmission electron micrographs, graphs showing anoxic growth in the presence of nitrite and a dendrogram comparing CFA profiles are available as supplementary material in IJSEM Online. 
DNA-DNA hybridization and/or phenotypic analysis allowed them to be differentiated from the two Pseudoxanthomonas species with validly published names and showed that strain $12-3^{\top}$ was genomically and phenotypically distinct from the other two isolates. On the basis of these results, two novel species of the genus Pseudoxanthomonas are proposed: Pseudoxanthomonas

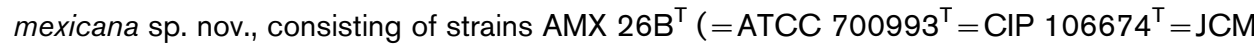
$11524^{\top}$ ) (type strain) and UR374_02 (=DSM 15133), and Pseudoxanthomonas japonensis sp. nov., consisting of strain $12-3^{\top}\left(=\mathrm{CCUG} 48231^{\top}=\mathrm{CIP} 107388^{\top}=\mathrm{JCM} 11525^{\top}\right)$. The report of these two novel species leads to the emendation of the description of the genus Pseudoxanthomonas and the re-evaluation of the phenotype of $P$. broegbernensis DSM $12573^{\top}$ necessitates the emendation of its description.

The creation of the genus Pseudoxanthomonas was initially based on the description of a single species, Pseudoxanthomonas broegbernensis, which shared phenotypic traits of Xanthomonas and Stenotrophomonas species (colour of the colonies, cell shape, Gram staining, presence of a branchedchain fatty acid pattern and of an ubiquinone with eight isoprenoid units) but which could be easily differentiated from them by its ability to reduce nitrite but not nitrate to $\mathrm{N}_{2} \mathrm{O}$ and by the lack of $\mathrm{C}_{13: 0}$ iso $3-\mathrm{OH}$ fatty acid characteristic of these genera (Yang et al., 1993; Finkmann et al., 2000; Assih et al., 2002). More recently, the isolation of two novel $\mathrm{N}_{2} \mathrm{O}$-producing strains from hot springs led to the description of a second species of the genus, Pseudoxanthomonas taiwanensis, which differs from $P$. broegbernensis mainly by the fact that it is not motile and that its optimum growth temperature is $50{ }^{\circ} \mathrm{C}$ instead of $30{ }^{\circ} \mathrm{C}$ (Chen et al., 2002). The two species also exhibit differences in the spectrum of substrates used and in their cellular fatty acid (CFA) profiles. Within the framework of a study on the role of aerobic bacteria in anaerobic digesters, a strain identified as AMX $26 \mathrm{~B}^{\mathrm{T}}$ was isolated in Mexico. This strain could not be assigned to any known species on the base of classical biochemical tests (conventional and API 20NE, Biotype 100) and CFA profiles. Analysis of its $16 \mathrm{~S}$ rRNA gene sequence revealed that it was closely related to a strain $\left(12-3^{\mathrm{T}}\right)$ previously isolated in Japan (Iizuka et al., 1998) and also to another strain (UR374_02) isolated in Germany and that it was moderately related to $P$. broegbernensis. In order to clarify their taxonomic position, all strains were subjected to more detailed study. In this paper, we report the characterization of two novel species of Pseudoxanthomonas, Pseudoxanthomonas mexicana sp. nov., including strains AMX $26 \mathrm{~B}^{\mathrm{T}}$ and UR374_02, and Pseudoxanthomonas japonensis sp. nov., including strain $12-3^{\mathrm{T}}$.

\section{Isolation and cultivation}

Unless otherwise indicated, isolation and culture of microorganisms to perform phenotypic tests were done under aerobic conditions at $35^{\circ} \mathrm{C}, \mathrm{pH}$. All analyses were performed at least in duplicate. AMX $26 \mathrm{~B}^{\mathrm{T}}$ was isolated from a laboratory-scale upflow anaerobic sludge blanket (UASB) reactor treating the wastewater of a cheese factory. Isolation was performed by serial dilution of grounded reactor sludge in a buffered salt solution $\left(\mathrm{g} \mathrm{l}^{-1}\right.$ : $\left.\mathrm{MgCl}_{2} \cdot 6 \mathrm{H}_{2} \mathrm{O}, 0 \cdot 405 ; \mathrm{KH}_{2} \mathrm{PO}_{4}, 0 \cdot 042 ; \mathrm{pH} 7 \cdot 2\right)$ and surface inoculation of Petri dishes containing medium R2A with $0 \cdot 1 \mathrm{ml}$ of the highest dilutions $\left(10^{-5}-10^{-10}\right)$. Purification was later obtained by streaking single colonies on Petri dishes filled with the same medium. Strain UR374_02 was isolated from the urine of a 10-year-old boy presenting bladder extrophy, a congenital birth defect that requires long-term catheterization and may occasionally cause urinary tract infections. As a routine follow up of the patient, $1 \mu$ l urine was plated on trypticase soy agar (TSA) supplemented with $5 \%(\mathrm{v} / \mathrm{v})$ sheep blood and incubated at $37^{\circ} \mathrm{C}$. Strain $12-3^{\mathrm{T}}$ was obtained from a sample of polluted urban soil, collected at the riverside of the Tamagawa river in the Tokyo metropolitan area, Japan, after a procedure (direct plating following filtration through a $0.45 \mu \mathrm{m}$ membrane without enrichment) specially designed to select for extremely small, free-living bacteria. A detailed description of the isolation and purification procedures for this strain is given by Iizuka et al. (1998).

\section{5 rRNA gene sequence analyses, DNA-DNA hybridization and $G+C$ content}

DNA extraction, 16S rRNA gene amplification, purification and sequencing were done as described previously by Assih et al. (2002) for strain AMX 26B ${ }^{\mathrm{T}}$, Iizuka et al. (1998) for strain $12-3^{\mathrm{T}}$ and Relman et al. (1992) for strain UR374_02. A non-redundant BLASTN search of full sequences through GenBank (Altschul et al., 1990; Benson et al., 1999) identified the closest relatives. Sequences used in the phylogenetic analysis were obtained from the RDP II (Maidak et al., 2001) and GenBank (Benson et al., 1999). The alignment was produced by importing sequences into BioEdit version 5.0.9 (Hall, 1999) and using the RDP II Sequence Aligner program (Maidak et al., 2001). Positions of sequence and alignment ambiguity were omitted and a masked dataset of 1410 unambiguous nucleotides was produced. Pairwise evolutionary distances were calculated using the method of Jukes \& Cantor (1969). Dendrograms were constructed using the neighbour-joining method (Saitou \& Nei, 1987) as implemented in the TreeCon for Windows package (Van de Peer \& De Wachter, 1994). Confidence in the tree topology was determined by bootstrapping 100 replicates (Felsenstein, 1985) and expressed as a percentage near the 
branching point. Determination of $\mathrm{G}+\mathrm{C}$ content and DNA renaturation studies were performed by the DSMZ using HPLC and spectrophotometric methods, respectively, as described by Assih et al. (2002). Hybridization percentages obtained by the spectrophotometric technique presented a standard deviation of less than $2.5 \%$. In any case, hybridizations between 60 and $75 \%$ were repeated in order to confirm the results.

$16 \mathrm{~S}$ rRNA gene sequences of 1464, 1466 and 1540 nucleotides, respectively, were determined for strains $12-3^{\mathrm{T}}$, UR374_02 and AMX $26 \mathrm{~B}^{\mathrm{T}}$. Phylogenetic analysis revealed that the three isolates clustered within the XanthomonasStenotrophomonas-Pseudoxanthomonas branch of the Proteobacteria (Fig. 1). The sequences of isolates AMX $26 \mathrm{~B}^{\mathrm{T}}$ and UR374_02 were $100 \%$ identical and they both shared $99 \cdot 6 \%$ similarity with that of strain $12-3^{\mathrm{T}}$. The three strains were related almost equidistantly to Xanthomonas $(95 \cdot 4-96 \cdot 6 \%)$ and Stenotrophomonas $(95 \cdot 3-96 \cdot 1 \%)$ species. P. broegbernensis DSM $12573^{\mathrm{T}}$, which shared $97 \cdot 5 \%$ sequence similarity with strains AMX $26 \mathrm{~B}^{\mathrm{T}}$ and UR374_02 and $97 \cdot 1 \%$ with strain $12-3^{\mathrm{T}}$, appeared to be their closest described relative. Within the genus Pseudoxanthomonas, the strains were only moderately related to $P$. taiwanensis ATCC BAA- $4040^{\mathrm{T}}(95 \cdot 3-95 \cdot 4 \%$ similarity), which was itself only moderately related to $P$. broegbernensis DSM $12573^{\mathrm{T}}$ ( $95 \cdot 8 \%$ similarity). In order to clarify definitively the phylogenetic position of the three isolates, DNA-DNA

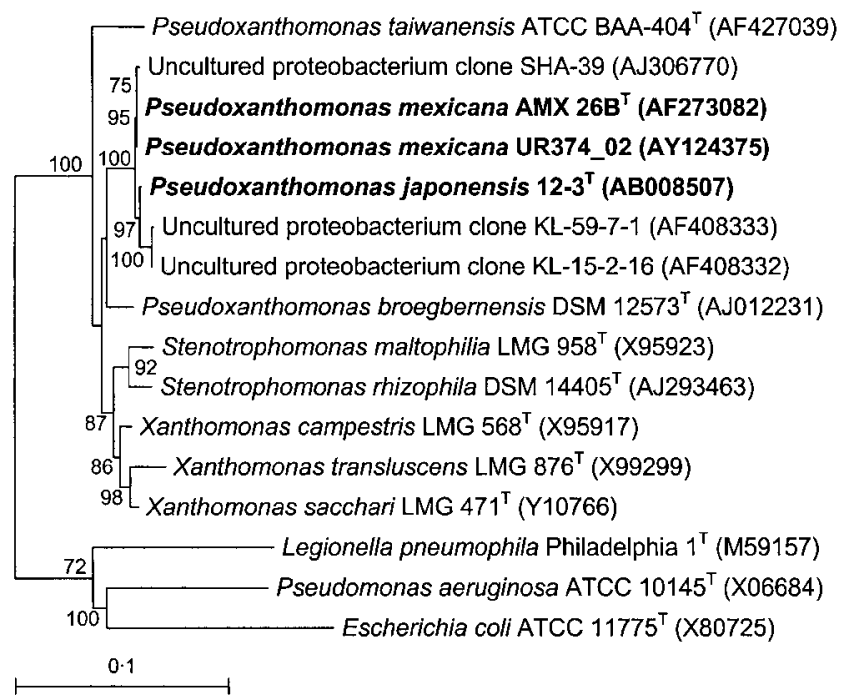

Fig. 1. Phylogenetic dendrogram based on $16 \mathrm{~S}$ rRNA gene sequences showing the position of $P$. mexicana sp. nov. AMX $26 \mathrm{~B}^{\top}$ and UR374_02 and $P$. japonensis sp. nov. 12-3 ${ }^{\top}$ within the genus Pseudoxanthomonas. The tree was constructed using the neighbour-joining method based on a masked dataset of 1410 nucleotides. Each bootstrap is represented as a percentage of 100 replicates. Values above $70 \%$ are given at branching points. Accession numbers are shown in parentheses. Bar, $10 \%$ sequence divergence. hybridization experiments were performed between them and with P. broegbernensis DSM $12573^{\mathrm{T}}$. Strain AMX $26 \mathrm{~B}^{\mathrm{T}}$ hybridized at $80 \cdot 4 \%$ with UR374_02 and $58 \cdot 7-61 \cdot 3 \%$ with $12-3^{\mathrm{T}}$. It showed a much lower level of hybridization with P. broegbernensis DSM $12573^{\mathrm{T}}(33.7 \%)$, similar to that observed between this species and strain $12-3^{\mathrm{T}}(37 \%)$. The DNA $\mathrm{G}+\mathrm{C}$ content of the isolates is given in the species description and was similar to that of the two Pseudoxanthomonas species described to date.

\section{Morphological, biochemical and physiological characteristics}

The strain morphology and results of biochemical and physiological analyses are given in the genus and species descriptions as well as in Supplementary Fig. A (available in IJSEM Online) and Table 1. Cell morphology and motility were deduced from direct observations of fresh cultures using a Nikon phase-contrast microscope. The presence, number and position of flagella were determined by flagellar staining (Kodaka et al., 1982; Mayfield \& Inniss, 1977) and/ or transmission electron microscopy after negative staining. To detect the presence of spores, slant cultures of the strains were prepared on yeast-peptone medium and one drop of the condensation water at the bottom of the slants was observed by optical microscopy. Gram staining was performed according to Murray et al. (1994). The capacity of the strains to hydrolyse Tween 80 and ONPG as well as the presence of arginine dihydrolase and lysine and ornithine decarboxylases were determined using the traditional techniques outlined by Marchal et al. (1987). All other classical biochemical phenotypic tests were performed with conventional procedures in Petri plates or tubes as described by Smibert \& Krieg (1994). The ranges of temperature and $\mathrm{NaCl}$ concentration that allowed growth of the strains were examined on solid media. TSA, which contains $5 \mathrm{~g} \mathrm{NaCl} \mathrm{l}^{-1}$, was used for the temperature measurement, while nutrient agar was used for the salt concentration assay. For the range of $\mathrm{pH}$, a liquid medium (nutrient broth with no $\mathrm{NaCl}$ added) was utilized instead of a solid one. The profile of substrates used by the strains was obtained by inoculating API 20NE (12 carbon sources) and Biotype 100 (98 carbon sources) strips according to the manufacturer's instructions (bioMérieux). The strips were incubated at $30^{\circ} \mathrm{C}$ and the readings were done after 1-4 days. The API 20NE strips also allowed crosschecking of some of the classical phenotypic tests and presented 11 common substrates with Biotype 100. A good correlation was found between these different tests, since a discrepancy was only observed for gelatin hydrolysis in the case of strain $12-3^{\mathrm{T}}$.

The isolates were able to use 17-24 of the 99 substrates assayed (Table 1). Strain UR374_02 appeared to be the least versatile and the most fastidious. It could use only 9-11 substrates when the Biotype test was performed with Biotype medium 1 and could use 21-22 substrates in the presence of medium Biotype 2, which contains more growth factors (37 instead of 16, including vitamins and amino 
Table 1. Morphological, biochemical and physiological characteristics of strains $A M X 26 B^{\top}$, UR374_02 and $12-3^{\top}$ compared with those of the type strains of Pseudoxanthomonas species

Strains: 1, P. mexicana sp. nov. AMX $26 \mathrm{~B}^{\mathrm{T}}$; 2, P. mexicana sp. nov. UR374_02; 3, P. japonensis sp. nov. 12-3 $3^{\mathrm{T}}$; 4, P. broegbernensis DSM $12573^{\mathrm{T}} ; 5$, P. taiwanensis ATCC BAA- $404^{\mathrm{T}}$. PNPG, $p$-Nitrophenyl $\beta$-D-galactoside; + , positive test or growth occurred; - , negative test or no growth; V, variable growth between duplicates; W, weak response; ND, not done. P. broegbernensis DSM $12573^{\mathrm{T}}$ and $P$. taiwanensis ATCC BAA $-404^{\mathrm{T}}$ shared the following characteristics with the isolates: presence of an aesculin and DNA hydrolase and ability to use as carbon sources D-cellobiose and D-glucose but not D-raffinose, L-rhamnose, glycerol, myo-inositol, D-sorbitol or D-malate. In addition, P. broegbernensis DSM $12573^{\mathrm{T}}$ shared with the isolates the following characteristics not tested for $P$. taiwanensis ATCC BAA-404 ${ }^{\mathrm{T}}$ : ability to use as growth substrates $\mathrm{N}$-acetyl-D-glucosamine, gentiobiose and maltotriose and inability to use several alcohols (adonitol, D-arabitol, L-arabitol, dulcitol, i-erythritol, D-mannitol, xylitol), amines (ethanolamine, tryptamine), amino acids (D-alanine, L-alanine, tryptophan), benzenic and heterocyclic aromatic compounds (benzoate, 3-hydroxybenzoate, 4-hydroxybenzoate, $m$-coumarate, gentisate, phenylacetate, 3-phenylpropionate, protocatechuate, trigonelline), organic acids (cis-aconitate, trans-aconitate, adipate, 5-aminovalerate, caprate, caprylate, D-galacturonate, D-gluconate, 2-ketogluconate, 5-ketogluconate, D-glucuronate, glutarate, DL-glycerate, itaconate, malonate, mucate, quinate, D-saccharate, L-tartrate, D-tartrate, meso-tartrate, tricarballylate) and sugars plus related compounds (L-fucose, hydroxyquinoline $\beta$-glucuronide, D-lyxose, D-melezitose, 1-O-methyl $\alpha$-galactoside, 3-O-methyl D-glucose, D-ribose, L-sorbose, D-tagatose) tested. Data for P. taiwanensis ATCC BAA$404^{\mathrm{T}}$ were taken from Chen et al. (2002). All the other data were determined in this study.

\begin{tabular}{|c|c|c|c|c|c|}
\hline Characteristic & 1 & 2 & 3 & 4 & 5 \\
\hline Flagellation (single and polar) and motility & + & + & + & + & - \\
\hline Catalase & $+\mathrm{w}$ & + & - & + & + \\
\hline Growth at $10^{\circ} \mathrm{C}$ & + & + & + & + & - \\
\hline Growth at $41^{\circ} \mathrm{C}$ & - & - & - & - & + \\
\hline Optimum temperature for growth & $30-37$ & $30-37$ & $30-37$ & 30 & 50 \\
\hline \multicolumn{6}{|l|}{ Hydrolysis of: } \\
\hline ONPG/PNPG & - & - & + & + & + \\
\hline Gelatin or casein & + & + & + & - & - \\
\hline Tween 80 & + & - & + & + & + \\
\hline \multicolumn{6}{|l|}{ Assimilation of carbon compounds } \\
\hline \multicolumn{6}{|l|}{ Sugars: } \\
\hline D-Fructose, D-mannose & + & - & - & + & - \\
\hline Lactose, D-melibiose, sucrose & - & - & - & + & - \\
\hline L-Arabinose & - & - & - & + & - \\
\hline D-Galactose & - & - & + & + & - \\
\hline Maltose & + & + & + & + & - \\
\hline D-Xylose & - & - & + & + & + \\
\hline D-Trehalose & + & - & + & + & + \\
\hline D-Glucosamine, lactulose & - & - & + & + & ND \\
\hline Maltitol, palatinose, D-turanose & - & - & - & + & ND \\
\hline \multicolumn{6}{|l|}{ Organic acids: } \\
\hline L-Malate & - & - & + & - & - \\
\hline Succinate & - & $+^{*}$ & + & - & - \\
\hline 4-Aminobutyrate & - & $+^{*}$ & $\mathrm{~V}$ & - & ND \\
\hline Citrate & - & - & - & + & ND \\
\hline 3-Hydroxybutyrate & + & $+^{*}$ & + & - & ND \\
\hline Fumarate & - & - & + & - & ND \\
\hline 2-Oxoglutarate & - & $+^{*}$ & - & - & ND \\
\hline DL-Lactate & - & $+^{*}$ & + & - & ND \\
\hline Propionate & + & + & + & - & ND \\
\hline \multicolumn{6}{|l|}{ Amino acids: } \\
\hline L-Glutamate & + & $+^{*}$ & + & - & + \\
\hline L-Proline & + & $+^{*}$ & - & + & + \\
\hline L-Serine & + & + & $\mathrm{V}$ & - & - \\
\hline L-Aspartate, L-histidine & + & $+^{*}$ & + & - & ND \\
\hline L-Tyrosine & - & $+^{*}$ & - & - & ND \\
\hline \multicolumn{6}{|l|}{ Others: } \\
\hline Histamine, putrescine & - & $+^{*}$ & - & - & ND \\
\hline
\end{tabular}

${ }^{\star}$ Growth occurred only with medium Biotype 2 . 
acids). Despite the poor carbon source utilization by the strains, several sugars, amino acids and organic acids supported growth (Table 1). The test performed on MEVAG medium indicated that glucose was metabolized by oxidation and that none of the strains, including $P$. broegbernensis DSM $12573^{\mathrm{T}}$, could ferment it.

Discrepancies were found between some of the characteristics reported in the original description of $P$. broegbernensis (Lipski et al., 1992; Finkmann et al., 2000) and observations in the present study: hydrolysis of aesculin (positive instead of negative), growth at $37^{\circ} \mathrm{C}$ and the use of L-arabinose, D-fructose and L-proline as carbon sources. Except for aesculin hydrolysis, however, our results are in line with those of Chen et al. (2002), who also re-evaluated the phenotype of this strain. Considering that P. broegbernensis DSM $12573^{\mathrm{T}}$ has repeatedly given a positive result in the aesculin hydrolysis assay performed in our different laboratories when using API 20NE and Biotype 100 strips but also in conventional tests in tubes or Petri plates, it seems that the negative result reported by Finkmann et al. (2000) is in fact restricted to the microtitration plate technique (Lipski et al., 1992) that they used to determine this parameter and the criteria that they selected to consider that the response to the test was positive or negative. Beyond the specific scope of this paper, this suggests that, in order to avoid evaluation-dependent phenotypes and so to improve stability in the description of strains, the use of widely available commercial kits or conventional techniques easily reproducible everywhere should be recommended for analysis of physiological properties.

\section{Nitrate and nitrite reduction}

The ability of the strains to reduce nitrate and nitrite was first investigated by the standard technique with the Griess reagent (Smibert \& Krieg, 1994) and Escherichia coli W3110 (=ATCC 27325), a bacterium able to reduce nitrate to nitrite but not nitrite, as a control. Since no clear and reproducible result could be obtained from the previous experiments between our different laboratories, despite the fact that the control worked well (the same situation was observed with the API 20NE $\mathrm{NO}_{3}^{-}$test), a new assay was prepared. This time, the strains were cultivated in trypticase soy broth (TSB), a medium of choice to study denitrification (Tiedje, 1988). The medium was prereduced by boiling and distributed under a nitrogen atmosphere in hermetically closed Hungate tubes. $\mathrm{NaNO}_{3}$ or $\mathrm{NaNO}_{2}$ was added to the tubes (three per strain and electron acceptor) immediately prior to inoculation $(10 \%$ $\mathrm{v} / \mathrm{v})$. Five concentrations were tested for $\mathrm{NO}_{2}^{-}(1 \cdot 47,5,10$, $15,20 \mathrm{mM})$ and one for $\mathrm{NO}_{3}^{-}(10 \mathrm{mM})$. One tube per strain was inoculated but not amended with either nitrate or nitrite. These tubes served as negative controls. Another series of tubes prepared with unreduced TSB under an air atmosphere was also inoculated to check the viability of the strains. Growth was followed daily or every 2-3 days by measuring $\mathrm{OD}_{580}$. The capacity of the strains to grow anoxically in presence of $\mathrm{NO}_{3}^{-}$or $\mathrm{NO}_{2}^{-}$but not in their absence was considered to indicate their ability to use them as electron acceptors. If no growth occurred after 46 days, the test was considered negative. Tubes showing growth were subcultured at least once in the same conditions in order to confirm the results. The reduction of $\mathrm{NO}_{3}^{-}$and $\mathrm{NO}_{2}^{-}$was later validated by measuring their final concentrations in the tubes using Quantofix nitrate/nitrite paper test sticks (Macherey-Nagel). The presence of $\mathrm{N}_{2} \mathrm{O}$ in the tube gas phase was also investigated qualitatively by $\mathrm{GC}$ with a thermal conductivity detector.

The three isolates showed the capacity to grow under anoxic conditions in the presence of nitrite at all the concentrations tested but not in its absence (Supplementary Fig. B; results for only some concentrations are shown) or in the presence of $10 \mathrm{mM}$ nitrate (data not shown). Less than $0.43 \mathrm{mM} \mathrm{NO}_{2}^{-}$was detected in the tubes initially amended with 5 and $10 \mathrm{mM} \mathrm{NO} \mathrm{NO}_{2}^{-}$after 46 days of incubation for the primary cultures and 25-30 days of incubation for the subcultures. At higher initial concentrations ( 15 and $20 \mathrm{mM}$ ), the amount of nitrite remaining in the tubes after the same length of time was above the upper concentration detectable $(1.74 \mathrm{mM})$ by the Quantofix test sticks. The presence of $\mathrm{N}_{2} \mathrm{O}$ in the gas phase of all the tubes containing nitrite definitively established the ability of the strains to reduce it. However, the conditions of the test, performed with a nitrogen atmosphere and a complex medium containing organic nitrogen that may liberate $\mathrm{NH}_{4}^{+}$upon degradation, did not allow us to determine whether nitrous oxide was the sole and final product of nitrite reduction. The growth efficiency of the three isolates under anoxic conditions with nitrite as the electron acceptor was much lower than under aerobic conditions. Indeed, the increase in OD was limited to $1 \cdot 2-1 \cdot 7$ times that of the inoculated control without added nitrite, while the maximal OD achieved represented only one-fifth to one-third of that reached in the aerobic viability controls. All the strains also presented a lag phase ranging from 4 to 12 days before starting to grow when transferred from an aerobic to an anoxic environment. This lag phase decreased or even disappeared upon subculturing anoxically with nitrite. P. broegbernensis DSM $12573^{\mathrm{T}}$, used as a positive control for $\mathrm{NO}_{2}^{-}$reduction and absence of $\mathrm{NO}_{3}^{-}$reduction, behaved similarly to the novel isolates. Nevertheless, its growth in the presence of $\mathrm{NO}_{2}^{-}$appeared to be much more efficient, since it was characterized by shorter lag phases, at least in the case of the primary cultures, and it attained higher OD for the same nitrite concentrations. In the case of $P$. broegbernensis DSM $12573^{\mathrm{T}}$, the maximal OD reached by the cultures increased with the concentration of nitrite (Supplementary Fig. B). This indicates that, in contrast to what was originally hypothesized (Finkmann et al., 2000), the reduction of nitrite to $\mathrm{N}_{2} \mathrm{O}$ by this strain is not only a detoxification process but is also coupled to energy production, since it influences the biomass yield. The positive correlation between OD and nitrite concentration was less evident for strains AMX 26B ${ }^{\mathrm{T}}$, UR374_02 and $12-3^{\mathrm{T}}$ (data not shown). Nevertheless, the fact that they 
could grow anoxically only in presence of this electron acceptor shows that they can also get energy from its reduction.

\section{Chemotaxonomic analyses}

The quinone systems of strains AMX $26 \mathrm{~B}^{\mathrm{T}}$ and $12-3^{\mathrm{T}}$ were extracted with an organic solvent mixture, evaporated, purified by TLC and separated by reverse-phase TLC (Hiraishi et al., 1984). Both strains were characterized by the absence of menaquinones and the presence of a ubiquinone with eight isoprenoid units as sole ubiquinone. The accuracy of this result was checked by extracting and analysing in parallel the quinones of $P$. broegbernensis DSM $12573^{\mathrm{T}}$, known to contain exclusively Q-8 (Lipski et al., 1992; Finkmann et al., 2000), as well as those of E. coli W3110 (=ATCC 27325), which contain MK-8 and Q-8.

The CFA composition was determined by Microbial ID using the fully automated GC Sherlock Microbial Identification System (MIDI) and MIDI standard procedures (Sasser, 1990) for strain cultivation $\left(24 \mathrm{~h}\right.$ at $28^{\circ} \mathrm{C}$ in TSB

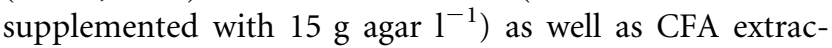
tion and analysis. Some 24-29 different CFA were detected in the novel isolates (Table 2). Nevertheless, eight to ten of them appeared only in very small amounts $(0 \cdot 07-0 \cdot 32 \%)$ and represented altogether less than $1.6 \%$ of the total CFA content. Saturated, hydroxy and unsaturated linear fatty acids were almost absent, while methyl-branched fatty acids corresponded to $66-71 \%$ of the total CFA. In order of decreasing abundance of this class were $\mathrm{C}_{15: 0}$ iso, $\mathrm{C}_{16: 0}$ iso, $\mathrm{C}_{11: 0}$ iso, $\mathrm{C}_{16: 1}$ iso $\mathrm{H}$ and $\mathrm{C}_{17: 0}$ iso. The branched, unsaturated fatty acid $\mathrm{C}_{17: 1}$ iso cis7 and the branched hydroxy fatty acid $\mathrm{C}_{11: 0}$ iso $3-\mathrm{OH}$ were also found in large amounts, particularly the first, which represented 18-20\% of the total fatty acid content. The branched saturated and branched hydroxy fatty acid patterns obtained for the three strains were similar to those of Xanthomonas and Stenotrophomonas species, but they lacked $\mathrm{C}_{13: 0}$ iso $3-\mathrm{OH}$. Qualitatively and quantitatively, the CFA profiles of the three strains were almost indistinguishable to the eye. Their comparison by unweighted arithmetic average clustering together with the CFA profiles of closely related species from the genera Pseudoxanthomonas, Stenotrophomonas and Xanthomonas showed that strains AMX $26 \mathrm{~B}^{\mathrm{T}}$ and UR374_02 had the most similar profiles, since they linked at a Euclidean distance of 3.9, and that they linked together at a distance of $6 \cdot 8$ with strain $12-3^{\mathrm{T}}$ (Supplementary Fig. C). This last value nevertheless remained well below the usual cut-off limit of 10 found by MIDI between species. In the same analysis, $P$. broegbernensis DSM $12573^{\mathrm{T}}$ linked with them at a Euclidean distance of over 25. Qualitatively, P. broegbernensis DSM $12573^{\mathrm{T}}$ can be distinguished from the novel isolates by the fact that it possesses unsaturated $\left(\mathrm{C}_{16: 1}\right.$ cis $7, \mathrm{C}_{17: 1}$ cis 9$)$ and hydroxy $\left(\mathrm{C}_{10: 0} 3-\mathrm{OH}, \mathrm{C}_{12: 0} 3-\mathrm{OH}\right)$ fatty acids and that, within the methyl-branched fatty acids, it contains $\mathrm{C}_{11: 0}$ anteiso but not $\mathrm{C}_{16: 1}$ iso $\mathrm{H}$ or $\mathrm{C}_{18: 1}$ iso $\mathrm{H}$. Quantitative differences can also be found. For instance, $\mathrm{C}_{16: 0}$ iso and $\mathrm{C}_{17: 1}$ iso cis7 are respectively $3-5$ and $1 \cdot 7-1 \cdot 9$ times more abundant in strains AMX $26 \mathrm{~B}^{\mathrm{T}}, \mathrm{UR} 374-02$ and $12-3^{\mathrm{T}}$ than in $P$. broegbernensis DSM $12573^{\mathrm{T}}$, while the latter strain contains 15-22 times more $\mathrm{C}_{16: 0}$ and $2 \cdot 4-3 \cdot 75$ times more $\mathrm{C}_{16: 1}$ cis $9 / \mathrm{C}_{15: 0}$ iso $2-\mathrm{OH}$ mixture than the others (Table 2). In addition, the ratio of $\mathrm{C}_{15: 0}$ iso/ $\mathrm{C}_{15: 0}$ anteiso is completely different between $P$. broegbernensis DSM $12573^{\mathrm{T}}$ and the three strains $(1 \cdot 89$ against $8 \cdot 5-19)$.

\section{Antibiotic susceptibility}

Susceptibility to antibiotics was tested using the KirbyBauer disc diffusion method (Bauer et al., 1966) on MuellerHinton solid medium (bioMérieux) with E. coli CIP 76.24 and Pseudomonas aeruginosa CIP 76.110 as controls. Inhibition diameters were recorded after $18-24 \mathrm{~h}$ incubation at $37^{\circ} \mathrm{C}$. MICs were extrapolated from the inhibition diameters using adapted software. The isolates showed a similar response and were found to be highly susceptible (low MIC values) to most of the antibiotics tested except those characterized by a mechanism of action based on the inhibition of protein synthesis and pipemidic acid, a quinolone, acting on the synthesis of nucleic acids (Table 3). Within the antibiotics that affect protein synthesis, the strains seemed to be particularly resistant (very high MIC) to the aminoglycosides but remained sensitive to doxycycline $\left(\mathrm{MIC}=0 \cdot 01 \mathrm{mg} \mathrm{l}^{-1}\right.$ ). Despite its medical origin, strain UR374_02 appeared to be the most susceptible of the three isolates. For instance, it presented low MICs for gentamicin, fusidic acid and erythromycin, in contrast to the others. Strain AMX $26 \mathrm{~B}^{\mathrm{T}}$ had the lowest MIC for penicillin G. P. broegbernensis DSM $12573^{\mathrm{T}}$ produced a susceptibility pattern completely different from those of the new isolates (Table 3). It was the only one to show low MICs to the aminoglycosides. Nevertheless, it must be noted that, among this antibiotic class, it was reported as resistant to gentamicin and kanamycin in the original published description (Finkmann et al., 2000). In the same study, it was also reported as resistant to penicillin G, while we found it susceptible. Since Finkmann et al. (2000) did not report MIC values or inhibition zone diameters for the antibiotics that they tested, and these parameters cannot be estimated from the given resistant and susceptible categories, their results are not in fact comparable to those obtained here. The antibiotic susceptibility profile presented in Table 3 for P. broegbernensis DSM $12573^{\mathrm{T}}$ therefore corresponds in reality to the first antibiogram defined on an adequate basis for this strain and which can serve as a reference for future comparisons.

\section{Taxonomic considerations}

The characterization of the three isolates clearly showed that they are phylogenetically affiliated to the genus Pseudoxanthomonas and that they possess the main phenotypic traits of its members. Nevertheless, within this group, the strains cannot be assigned to either of the two existing species. In particular, they cannot belong to $P$. taiwanensis, which is not motile, lacks flagellation, does not use maltose, 
Table 2. Fatty acid profiles of strains $A M X 26 B^{\top}$, UR374_02 and $12-3^{\top}$ and that of their closest phylogenetic relative, $P$. broegbernensis DSM $12573^{T^{\top}}$

Values are percentages of total fatty acids. tr, Trace, corresponding arbitrarily to less than $0 \cdot 34 \%$ of total CFA.

\begin{tabular}{|c|c|c|c|c|}
\hline Fatty acid & $A M X 26 B^{T}$ & UR374_02 & $12-3^{T}$ & P. broegbernensis DSM $12573^{\mathrm{T}}$ \\
\hline \multicolumn{5}{|l|}{ Saturated } \\
\hline $10: 0$ & $\operatorname{tr}$ & $\operatorname{tr}$ & $\operatorname{tr}$ & $0 \cdot 72$ \\
\hline $14: 0$ & $0 \cdot 40$ & $0 \cdot 34$ & $0 \cdot 38$ & $1 \cdot 79$ \\
\hline $15: 0$ & & & $\operatorname{tr}$ & $1 \cdot 15$ \\
\hline $16: 0$ & $0 \cdot 48$ & $0 \cdot 53$ & $0 \cdot 67$ & $10 \cdot 32$ \\
\hline \multicolumn{5}{|l|}{ Unsaturated } \\
\hline $15: 1$ cis7 & & & & $\operatorname{tr}$ \\
\hline $15: 1$ cis 9 & & & & $\operatorname{tr}$ \\
\hline $16: 1$ cis7 & & & & $0 \cdot 96$ \\
\hline $17: 1$ cis 11 & & & $\operatorname{tr}$ & \\
\hline $17: 1$ cis 9 & & & & $0 \cdot 67$ \\
\hline $18: 1$ cis 9 & & & & $\operatorname{tr}$ \\
\hline $18: 1$ cis 11 & $\operatorname{tr}$ & $\operatorname{tr}$ & $0 \cdot 48$ & $\operatorname{tr}$ \\
\hline \multicolumn{5}{|l|}{ Methyl-branched } \\
\hline $10: 0$ iso & $\operatorname{tr}$ & $\operatorname{tr}$ & $\operatorname{tr}$ & $\operatorname{tr}$ \\
\hline $11: 0$ iso & $5 \cdot 41$ & $4 \cdot 89$ & $4 \cdot 69$ & $5 \cdot 39$ \\
\hline $11: 0$ anteiso & & & & $0 \cdot 72$ \\
\hline $12: 0$ iso & $\operatorname{tr}$ & $\operatorname{tr}$ & $\operatorname{tr}$ & $\operatorname{tr}$ \\
\hline $13: 0$ iso & $\operatorname{tr}$ & $\operatorname{tr}$ & $\operatorname{tr}$ & $\operatorname{tr}$ \\
\hline $13: 0$ anteiso & & & & $\operatorname{tr}$ \\
\hline $14: 0$ iso & $2 \cdot 11$ & $2 \cdot 86$ & $2 \cdot 37$ & $0 \cdot 52$ \\
\hline $15: 1$ iso $F$ & $1 \cdot 30$ & $1 \cdot 63$ & $1 \cdot 49$ & $1 \cdot 49$ \\
\hline $15: 0$ iso & $39 \cdot 69$ & $36 \cdot 82$ & $32 \cdot 95$ & $26 \cdot 70$ \\
\hline $15: 0$ anteiso & $2 \cdot 57$ & $1 \cdot 94$ & $3 \cdot 85$ & $14 \cdot 12$ \\
\hline $16: 1$ iso $\mathrm{H}$ & $3 \cdot 89$ & $4 \cdot 91$ & $4 \cdot 05$ & \\
\hline $16: 0$ iso & $9 \cdot 70$ & $11 \cdot 79$ & $12 \cdot 67$ & $2 \cdot 57$ \\
\hline $17: 0$ iso & $4 \cdot 87$ & $3 \cdot 53$ & $3 \cdot 46$ & $3 \cdot 55$ \\
\hline $17: 0$ anteiso & $0 \cdot 39$ & $\operatorname{tr}$ & $0 \cdot 58$ & $0 \cdot 93$ \\
\hline $17: 0$ 10-methyl & $\operatorname{tr}$ & $\operatorname{tr}$ & & \\
\hline $18: 1$ iso $\mathrm{H}$ & $0 \cdot 72$ & $0 \cdot 77$ & $0 \cdot 72$ & \\
\hline \multicolumn{5}{|l|}{ Branched-chain unsaturated } \\
\hline $17: 1$ iso cis 7 & $18 \cdot 46$ & $18 \cdot 74$ & $19 \cdot 91$ & $10 \cdot 68$ \\
\hline $17: 1$ anteiso cis7 & $\operatorname{tr}$ & & $0 \cdot 46$ & $\operatorname{tr}$ \\
\hline \multicolumn{5}{|l|}{ Hydroxy } \\
\hline $10: 03-\mathrm{OH}$ & & & & $0 \cdot 38$ \\
\hline $11: 02-\mathrm{OH}$ & $\operatorname{tr}$ & & & \\
\hline $12: 03-\mathrm{OH}$ & & & & $0 \cdot 37$ \\
\hline $13: 02-\mathrm{OH}$ & & & & $\operatorname{tr}$ \\
\hline \multicolumn{5}{|l|}{ Branched-chain hydroxy } \\
\hline $11: 0$ iso $3-\mathrm{OH}$ & $6 \cdot 53$ & $6 \cdot 02$ & $5 \cdot 22$ & $5 \cdot 88$ \\
\hline $12: 0$ iso $3-\mathrm{OH}$ & $\operatorname{tr}$ & $\operatorname{tr}$ & $\operatorname{tr}$ & $\operatorname{tr}$ \\
\hline $13: 0$ iso $3-\mathrm{OH}$ & & & & $\operatorname{tr}$ \\
\hline \multicolumn{5}{|l|}{ Unresolved } \\
\hline $13: 03-\mathrm{OH} / 15: 1$ iso $\mathrm{I} / \mathrm{H}$ & $\operatorname{tr}$ & $\operatorname{tr}$ & $\operatorname{tr}$ & \\
\hline $16: 1$ cis $9 / 15: 0$ iso $2-\mathrm{OH}$ & $3 \cdot 15$ & $2 \cdot 9$ & $4 \cdot 47$ & $10 \cdot 86$ \\
\hline $17: 1$ iso $\mathrm{I} /$ anteiso $\mathrm{B}$ & $0 \cdot 34$ & $0 \cdot 7$ & $0 \cdot 48$ & \\
\hline
\end{tabular}

cannot hydrolyse proteins and is thermophilic, while the novel isolates possess these characteristics and are typically mesophilic (Table 1). Moreover, their 16S rRNA gene sequences show a difference of $4 \cdot 6-4 \cdot 7 \%$ from that of
P. taiwanensis ATCC BAA $-4040^{\mathrm{T}}$, which is greater than the $3 \%$ difference recognized as sufficient to separate bacteria in distinct species (Stackebrandt \& Goebel, 1994). The same criteria would indicate that all isolates could be members 
Table 3. MICs $\left(\mathrm{mg} \mathrm{l}^{-1}\right)$ of selected antibiotics against isolates $\mathrm{AMX} 26 \mathrm{~B}^{\top}$, UR374_02 and 12-3 ${ }^{\top}$ and $P$. broegbernensis DSM $12573^{\top}$

Antibiotics are listed under mode of action and class. Values in parentheses after the name of the antibiotics correspond to the disc charge. S, R and I in parentheses after the MICs mean that the strains are respectively susceptible, resistant or intermediately susceptible to the antibiotics based on the guidelines of CASFM (2002). Such classification is given simply as an indication and should be used with caution for novel species that were not considered in the definition of the clinical categories.

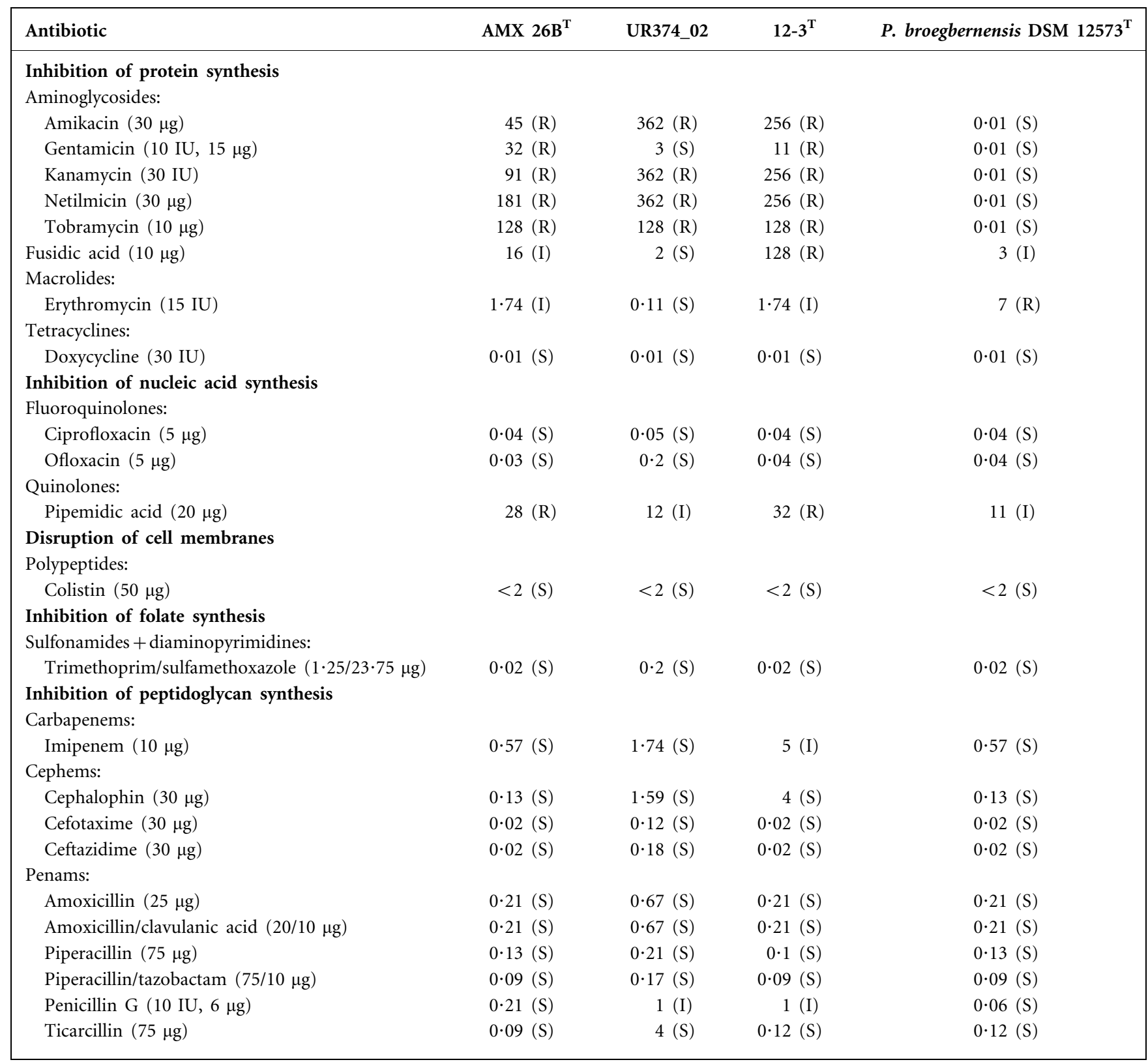

of $P$. broegbernensis, since their $16 \mathrm{~S}$ rRNA gene sequences have only $2 \cdot 5-2 \cdot 9 \%$ difference from that of $P$. broegbernensis DSM $12573^{\mathrm{T}}$. This conclusion is strengthened by the fact that the type strain of this species shares numerous phenotypic traits with the novel strains (see legend to Table 1), especially that of being mesophilic and motile by means of a single polar flagellum. Nevertheless, beside these similarities, strains AMX 26B ${ }^{\mathrm{T}}$, UR374_02 and 12-3 ${ }^{\mathrm{T}}$ present more phenotypic differences from $P$. broegbernensis
DSM $12573^{\mathrm{T}}$ at the level of substrate utilization (at least 13 differences, when each strain uses only 17-24 carbon sources of the 99 tested), CFA composition and antibiotic susceptibility. These differences, combined with the fact that the DNA of strains AMX $26 \mathrm{~B}^{\mathrm{T}}$ and $12-3^{\mathrm{T}}$ hybridized with that of $P$. broegbernensis DSM $12573^{\mathrm{T}}$ at a level significantly below the value of $70 \%$ proposed for species delineation (Wayne et al., 1987; Stackebrandt et al., 2002), support definitively the conclusion that these novel isolates 
are not members of this species. DNA-DNA hybridization also revealed that the three strains could be divided in two genomic groups. The first was composed of AMX $26 \mathrm{~B}^{\mathrm{T}}$ and UR374_02 and the second of $12-3^{\mathrm{T}}$. The two genomic groups could not be easily distinguished by their morphology, antibiotic susceptibility or CFA profiles. Notwithstanding this observation, and despite the heterogeneous biochemical profile presented by the members of the first group (Table 1), strain $12-3^{\mathrm{T}}$ could be clearly distinguished from it by other phenotypic properties such as a catalasenegative reaction, the inability to grow in the presence of $40 \mathrm{~g} \mathrm{NaCl} \mathrm{l}^{-1}$ and the capacity to hydrolyse ONPG/PNPG and to use D-galactose, D-glucosamine, lactulose, D-xylose, fumarate and L-malate as carbon sources but not L-proline (Table 1).

Taking into account the phenotypic and phylogenetic characteristics described above, we propose that strains AMX 26B ${ }^{\mathrm{T}}$ and UR374_02 represent a novel species within the genus Pseudoxanthomonas, Pseudoxanthomonas mexicana sp. nov., with $\mathrm{AMX} 26 \mathrm{~B}^{\mathrm{T}}$ as the type strain, and that strain $12-3^{\mathrm{T}}$ represents another novel species of the genus, Pseudoxanthomonas japonensis sp. nov. The genus Pseudoxanthomonas now contains four species. Three of them, $P$. broegbernensis, $P$. japonensis and P. mexicana, form a phenotypically and phylogenetically homogeneous group, since they are all mesophilic and motile by means of a single polar flagellum and share $97 \cdot 1-99 \cdot 6 \% 16 \mathrm{~S}$ rRNA gene sequence similarity. In this scheme, the thermophilic and non-motile $P$. taiwanensis appears isolated. The phylogenetic distance $(>4.5 \%$ difference in $16 \mathrm{~S}$ rRNA gene sequence) that separates it from the others indicates that a new genus could be set up to accommodate it. Nevertheless, this splitting appears premature, since only one thermophilic Pseudoxanthomonas species has been described so far. As a consequence, it seems judicious to wait for the description of more thermophilic and mesophilic Pseudoxanthomonas species, in order to determine whether they clearly form two independent homogeneous groups. In any case, the additional information brought by the description of $P$. japonensis and $P$. mexicana and also the reevaluation of the phenotype of $P$. broegbernensis DSM $12573^{\mathrm{T}}$ in this work indicate the necessity of emending the descriptions of the genus Pseudoxanthomonas and $P$. broegbernensis. The new data brought by the recent description of $P$. taiwanensis will be also incorporated in the emended description of the genus.

\section{Ecological aspects}

The isolation of strains AMX $26 \mathrm{~B}^{\mathrm{T}}$, UR374_02 and 12-3 ${ }^{\mathrm{T}}$ broadens the number of biotopes known to be occupied by Pseudoxanthomonas species and indicates that they are widely distributed over the world, since they have been found in three continents (Europe, Asia and America). The case of $P$. mexicana also shows that each species may colonize different environments. The presence of this species in an anaerobic digester seems on first inspection to be casual. Indeed, its growth under anoxic conditions is only possible with nitrite as the electron acceptor, a compound unlikely to be found in sufficient concentrations in the cheese factory effluent used to feed the reactor. This suggests that $P$. mexicana was probably introduced in this biotope as a transient micro-organism through the wastewater. Nevertheless, it is surprising to see that an as-yet uncultured bacterium (clone SH-39) phylogenetically very close to $P$. mexicana $(99 \cdot 7 \% 16 \mathrm{~S}$ rRNA gene sequence similarity; Fig. 1) was also detected in an anaerobic reactor (Schlötelburg, 2001) and that other respiratory denitrifiers have been found to survive for very long periods of time (even years) in such nitrate-/nitrite-free anaerobic environments (Jørgensen \& Tiedje, 1993). The question then remains open as to whether this species can or can not be an autochthonous member of the microflora of this biotope, as was previously observed in the case of another denitrifying member of the family Xanthomonadaceae, Stenotrophomonas acidaminiphila (Assih et al., 2002). The presence of $P$. mexicana UR374_02 in the urine of a child at a titre compatible with urinary tract infections $\left(10^{5}\right.$ c.f.u. $\mathrm{ml}^{-1}$ ) also raises the question of its potential role (and that of other Pseudoxanthomonas species) as an opportunistic pathogen. The fact that it was obtained in mixed culture with environmental or saprophytic bacterial species (Enterococcus sp., Acinetobacter sp., coagulase-negative staphylococci and Corynebacterium sp.) and the absence of infective signs at the moment of isolation suggest that it came from contamination (i.e. saprophytic skin flora) and propagated in the bag used to collect the catheter urine. P. mexicana therefore appears not to have clinical significance. In any case, it seems to be highly susceptible to treatment by antibiotics, as are the other mesophilic Pseudoxanthomonas species. It is also worth noting that, similarly to P. mexicana, uncultured bacteria (clones KL-152-16 and KL-59-7-1) phylogenetically close to P. japonensis (99-2-99.3 \% 16S rRNA gene sequence similarity; Fig. 1) have been found in a completely different biotope (spacecraft assembly facilities). This suggests that novel strains belonging to the known species should soon be isolated or that novel species of the genus should be described.

\section{Emended description of the genus Pseudoxanthomonas Finkmann et al. 2000}

Members of the genus are non-spore-forming rods, usually $0 \cdot 4-0 \cdot 8 \times 0 \cdot 9-1.5 \mu \mathrm{m}$, which stain Gram-negative. They have a strictly respiratory type of metabolism with $\mathrm{O}_{2}$ as preferential terminal electron acceptor and can reduce nitrite but not nitrate. $\mathrm{N}_{2} \mathrm{O}$ is always a main product of nitrite reduction if not the only one. Most species are mesophilic (optimum temperature $30-37^{\circ} \mathrm{C}$ ), slightly alkalophilic (optimum pH over 7 and preferentially around 8 ) and motile by means of a single polar flagellum; however, one species is thermophilic (optimum temperature $50{ }^{\circ} \mathrm{C}$ ) and non-motile. Colonies on solid media are generally yellow to pale yellow or beige. Oxidase-positive and heterotrophic. They use a limited range of carbon sources, including some sugars, organic and amino acids. 
The cellular fatty acids are of the iso/anteiso type with 15:0 iso normally predominating and 13:0 iso $3-\mathrm{OH}$ always absent. Quinones are generally of the Q8 type. DNA G + C content is $65-70 \mathrm{~mol} \%$. Members of the genus are widely distributed in nature. The type species is Pseudoxanthomonas broegbernensis.

\section{Emended description of Pseudoxanthomonas broegbernensis Finkmann et al. 2000}

Exhibits all of the characteristics of the mesophilic members of the genus. Tests for catalase and hydrolysis of ONPG/ PNPG, aesculin, DNA and Tween 80 are positive, while those for gelatin, starch and urea hydrolysis, indole production, lysine and ornithine decarboxylase but also arginine dihydrolase are negative. Substrates utilized and susceptibility to antibiotics are detailed in Tables 1 and 3. Can be distinguished from the other mesophilic species by its ability to use L-arabinose, lactose, maltitol, D-melibiose, palatinose, sucrose, D-turanose and citrate. Predominant fatty acids are, in decreasing abundance, 15:0 iso, 15:0 anteiso, 16:1 cis9, 17:1 iso cis7 and 16:0. The fatty acid 17:0 cyclo is absent. Reduces nitrite to nitrous oxide as sole end product. Growth is possible with $0-40 \mathrm{~g} \mathrm{NaCl}^{-1}$, at $10-37^{\circ} \mathrm{C}$ and $\mathrm{pH} 6 \cdot 5-9 \cdot 75$ and is optimal at $30^{\circ} \mathrm{C}$, $\mathrm{pH} 8$ and without $\mathrm{NaCl}$. The DNA $\mathrm{G}+\mathrm{C}$ content is $66 \cdot 5 \pm 0 \cdot 8 \mathrm{~mol} \%$.

The type strain, B1616/1 $1^{\mathrm{T}}\left(=\right.$ ATCC BAA $-10^{\mathrm{T}}=$ CCUG $46890^{\mathrm{T}}=\mathrm{CIP} 107227^{\mathrm{T}}=$ DSM $12573^{\mathrm{T}}$ ), was isolated from an experimental biofilter supplied with the waste gas of an animal-rendering plant.

\section{Description of Pseudoxanthomonas mexicana sp. nov.}

Pseudoxanthomonas mexicana (me.xi.ca'na. N.L. fem. adj. mexicana pertaining to Mexico, where the type strain was isolated).

Exhibits all of the characteristics of the mesophilic members of the genus. Tests for catalase and hydrolysis of aesculin, gelatin and DNA are positive, while those for ONPG/PNPG and urea hydrolysis, indole production, lysine and ornithine decarboxylase as well as arginine dihydrolase are negative. Tween 80 and starch hydrolysis may give a positive or negative result depending on the strain. The spectrum of substrates utilized is listed in Table 1; it may fluctuate from strain to strain. Members of this species can be distinguished from the other mesophilic species by their inability to use D-galactose, D-glucosamine, lactulose and D-xylose. Susceptible to most classes of antibiotics except aminoglycosides. Predominant fatty acids are, in decreasing abundance, $15: 0$ iso, $17: 1$ iso cis7, $16: 0$ iso, $11: 0$ iso $3-\mathrm{OH}$ and $11: 0$ iso. Growth is possible with $0-40 \mathrm{~g} \mathrm{NaCl} \mathrm{l}^{-1}$, at $10-37^{\circ} \mathrm{C}$ and $\mathrm{pH} 5 \cdot 8-9 \cdot 75$ and is optimal at $30-37^{\circ} \mathrm{C}$, $\mathrm{pH} 7-8$ and without $\mathrm{NaCl}$. The DNA $\mathrm{G}+\mathrm{C}$ content is $67 \cdot 8 \pm 2 \mathrm{~mol} \%$.

The type strain, AMX $26 \mathrm{~B}^{\mathrm{T}}\left(=\mathrm{ATCC} 700999^{\mathrm{T}}=\mathrm{CIP}\right.$
$106674^{\mathrm{T}}=\mathrm{JCM} 11524^{\mathrm{T}}$ ), was isolated from the sludge of an anaerobic reactor treating the wastewater of a cheese factory. Strain UR374_02 (=DSM 15133) was isolated from the urine of a child.

\section{Description of Pseudoxanthomonas japonensis sp. nov.}

Pseudoxanthomonas japonensis (ja.po.nen'sis. N.L. fem. adj. japonensis pertaining to Japan, where the type strain was isolated).

Exhibits all of the characteristics of the mesophilic members of the genus. Tests for the hydrolysis of ONPG/PNPG, aesculin, gelatin, DNA and Tween 80 are positive, while those for starch and urea hydrolysis, catalase, indole production, lysine and ornithine decarboxylase but also arginine dihydrolase are negative. The spectrum of substrates used is listed in Table 1. Can be distinguished from the other mesophilic species by its ability to use fumarate and L-malate but not L-proline. Susceptible to most classes of antibiotics except aminoglycosides, fusidic acid and pipemidic acid. Predominant fatty acids are, in decreasing abundance, $15: 0$ iso, $17: 1$ iso cis7, $16: 0$ iso and $11: 0$ iso 3-OH. Growth is possible with $0-30 \mathrm{~g} \mathrm{NaCl}{ }^{-1}$, at $10-37^{\circ} \mathrm{C}$ and $\mathrm{pH} 6 \cdot 2-9 \cdot 5$ and is optimal at $30-37^{\circ} \mathrm{C}, \mathrm{pH} 8$ and without $\mathrm{NaCl}$. The DNA G $+\mathrm{C}$ content is $65 \cdot 2 \pm 1 \mathrm{~mol} \%$.

The type strain, $12-3^{\mathrm{T}}\left(=\right.$ CCUG $48231^{\mathrm{T}}=$ CIP $107388^{\mathrm{T}}=$ JCM $\left.11525^{\mathrm{T}}\right)$, was isolated from polluted urban soil.

\section{Acknowledgements}

Financial support provided by IRD to S. T. and A.S. O. and by the Secretaria de Relaciones Exteriores (Foreign Affairs) of Mexico to S. T. is gratefully acknowledged. Many thanks are due to Anne Le Flèche (Pasteur Institute; biochemical tests), Florence Megglé and Marie Christine Bray (Alphabio; antibiogram), Karen Dohrman (Microbial ID; CFA analysis), John Bartell (MIDI Labs; 16S rDNA sequencing) and Peter Schumann (DSMZ; G + C and DNA-DNA hybridization) for their professional and fine suggestions on the techniques that they performed for us on a commercial basis. Thanks are also due to Jean-Louis Garcia, Bernard Ollivier, Yannick Combet-Blanc and Jean Lemer for fruitful discussions on taxonomy, phylogeny and many other topics, to Bernard La Scola for advice on antibiogram interpretation and to Jean-Luc Cayol for the preliminary analysis of the 16S rRNA gene sequence of strain AMX $26 \mathrm{~B}^{\mathrm{T}}$ and for its submission to GenBank. All our gratitude goes to Monica Bonilla, Marie-Laure Fardeau, Ashish Jhina and Nicolas Bernet for their decisive contributions to the identification of the final products of nitrite reduction. We also appreciated very much the help of André Lipski and Guang-Huey Lin, who always kindly answered our questions about the strains of $P$. broegbernensis and P. taiwanensis that they respectively described. Finally, we are indebted with Paulino Rivas, Omar Reyes and Abelardo Villareal of Quesos Caperucita who provided the sludge and wastewater used to operate the reactor from which strain AMX $26 \mathrm{~B}^{\mathrm{T}}$ was isolated.

\section{References}

Altschul, S. F., Gish, W., Miller, W., Myers, E. W. \& Lipman, D. J. (1990). Basic local alignment search tool. J Mol Biol 215, 403-410. 
Assih, E. A., Ouattara, A. S., Thierry, S., Cayol, J.-L., Labat, M. \& Macarie, H. (2002). Stenotrophomonas acidaminiphila sp. nov., a strictly aerobic bacterium isolated from an upflow anaerobic sludge blanket (UASB) reactor. Int J Syst Evol Microbiol 52, 559-568.

Bauer, A. W., Kirby, W. M. M., Sherris, J. C. \& Turk, M. (1966). Antibiotic susceptibility testing by a standardized single disk method. Am J Clin Pathol 45, 493-496.

Benson, D. A., Boguski, M. S., Lipman, D. J., Ostell, J., Ouellette, B. F., Rapp, B. A. \& Wheeler, D. L. (1999). GenBank. Nucleic Acids Res 27, 12-17.

CASFM (2002). Communiqué 2002. Special number SFM, pp. 1-47. Paris: Comité de l'antibiogramme de la Société Française de Microbiologie (in French). http://www.sfm.asso.fr

Chen, M.-Y., Tsay, S.-S., Chen, K.-Y., Shi, Y.-C., Lin, Y.-T. \& Lin, G.-H. (2002). Pseudoxanthomonas taiwanensis sp. nov., a novel thermophilic, $\mathrm{N}_{2} \mathrm{O}$-producing species isolated from hot springs. Int J Syst Evol Microbiol 52, 2155-2161.

Felsenstein, J. (1985). Confidence limits on phylogenies: an approach using the bootstrap. Evolution 39, 783-791.

Finkmann, W., Altendorf, K., Stackebrandt, E. \& Lipski, A. (2000). Characterization of $\mathrm{N}_{2} \mathrm{O}$-producing Xanthomonas-like isolates from biofilters as Stenotrophomonas nitritireducens sp. nov., Luteimonas mephitis gen. nov., sp. nov. and Pseudoxanthomonas broegbernensis gen. nov., sp. nov. Int J Syst Evol Microbiol 50, 273-282.

Hall, T. A. (1999). BioEdit: a user-friendly biological sequence alignment editor and analysis program for Windows 95/98/NT. Nucleic Acids Symp Ser 48, 95-98.

Hiraishi, A., Hoshino, Y. \& Kitamura, H. (1984). Isoprenoid quinone composition in the classification of Rhodospirillaceae. J Gen Appl Microbiol 30, 197-210.

lizuka, T., Yamanaka, S., Nishiyama, T. \& Hiraishi, A. (1998). Isolation and phylogenetic analysis of aerobic copiotrophic ultramicrobacteria from urban soil. J Gen Appl Microbiol 44, 75-84.

Jørgensen, K. S. \& Tiedje, J. M. (1993). Survival of denitrifiers in nitrate-free, anaerobic environments. Appl Environ Microbiol 59, 3297-3305.

Jukes, T. H. \& Cantor, C. R. (1969). Evolution of protein molecules. In Mammalian Protein Metabolism, vol. 3, pp. 21-132. Edited by H. N. Munro. New York: Academic Press.

Kodaka, H., Armfield, A. Y., Lombard, G. L. \& Dowell, V. R. (1982). Practical procedure for demonstrating bacterial flagella. $J$ Clin Microbiol 16, 948-952.

Lipski, A., Klatte, S., Bendinger, B. \& Altendorf, K. (1992). Differentiation of Gram-negative, non fermentative bacteria isolated from biofilters on the basis of fatty acid composition, quinone system, and physiological reaction profile. Appl Environ Microbiol 58, 2053-2065.

Maidak, B. L., Cole, J. R., Lilburn, T. G. \& 7 other authors (2001). The RDP-II (Ribosomal database project). Nucleic Acids Res 29, 173-174.
Marchal, N., Bourdon, J. L. \& Richard, C. (1987). Culture Medium for the Isolation and Biochemical Identification of Bacteria, 3rd edn. Paris: Doin Editeurs (in French).

Mayfield, C. I. \& Inniss, W. E. (1977). A rapid, simple method for staining bacterial flagella. Can J Microbiol 23, 1311-1313.

Murray, R. G. E., Doetsch, R. N. \& Robinow, C. F. (1994). Determinative and cytological light microscopy. In Methods for General and Molecular Bacteriology, pp. 21-41. Edited by P. Gerhardt, R. G. E. Murray, W. A. Wood \& N. R. Krieg. Washington, DC: American Society for Microbiology.

Relman, D. A., Lepp, P. W., Sadler, K. N. \& Schmidt, T. M. (1992). Phylogenetic relationships among the agent of bacillary angiomatosis, Bartonella bacilliformis, and other alpha-proteobacteria. Mol Microbiol 6, 1801-1807.

Saitou, N. \& Nei, M. (1987). The neighbor-joining method: a new method for reconstructing phylogenetic trees. Mol Biol Evol 4, 406-425.

Sasser, M. (1990). Identification of bacteria through fatty acid analysis. In Methods in Phytobacteriology, pp. 119-204. Edited by Z. Klement, K. Rudolph \& D. C. Sands. Budapest: Akademiai Kiado. Schlötelburg, C. (2001). Microbial diversity and dynamic in a 1,2dichloropropane dechlorinating mixed culture. $\mathrm{PhD}$ thesis, HumboldtUniversity, Berlin, Germany (in German). http://dochost.rz.hu-berlin. de/abstract.php3/dissertationen/schloetelburg

Smibert, R. M. \& Krieg, W. R. (1994). Phenotypic characterization. In Methods for General and Molecular Bacteriology, pp. 607-654. Edited by P. Gerhardt, R. G. E. Murray, W. A. Wood \& N. R. Krieg. Washington, DC: American Society for Microbiology.

Stackebrandt, E. \& Goebel, B. M. (1994). Taxonomic note: a place for DNA-DNA reassociation and 16S rRNA sequence analysis in the present species definition in bacteriology. Int J Syst Bacteriol 44, 846-849.

Stackebrandt, E., Frederiksen, W., Garrity, G. M. \& 10 other authors (2002). Report of the ad hoc committee for the re-evaluation of the species definition in bacteriology. Int J Syst Evol Microbiol 52, 1043-1047.

Tiedje, J. M. (1988). Ecology of denitrification and dissimilatory nitrate reduction to ammonium. In Biology of Anaerobic Microorganisms, pp. 179-244. Edited by A. J. M. Zenhder. Chichester: Wiley.

Van de Peer, Y. \& De Wachter, R. (1994). TREECON for Windows: a software package for the construction and drawing of evolutionary trees for the Microsoft Windows environment. Comput Appl Biosci 10, 569-570.

Wayne, L. G., Brenner, D. J., Colwell, R. R. \& 9 other authors (1987). International Committee on Systematic Bacteriology. Report of the ad hoc committee on reconciliation of approaches to bacterial systematics. Int J Syst Bacteriol 37, 463-464.

Yang, P., Vauterin, L., Vancanneyt, M., Swings, J. \& Kersters, K. (1993). Application of fatty acid methylesters for the taxonomic analysis of the genus Xanthomonas. Syst Appl Microbiol 16, 47-71. 